\title{
Mortalitas Induk dan Anak Sapi Saat Partus Pada Program Inseminasi Buatan (Studi Kasus Program Inseminasi Buatan di Kecamatan Sinjai Barat)
}

\author{
Mortality of Cattle Cows and Calfs When Parturitation in the Artificial Insemination \\ Programs (Case Study of Artificial Insemination \\ Programs in Sinjai Barat District) \\ Jumriah Syam $^{1 *}$, Zulfah Nur' ${ }^{1}$ Junaedi $^{2}$ \\ ${ }^{1}$ Jurusan Ilmu Peternakan Fak Sains dan Teknologi UIN Alauddin Makassar \\ ${ }^{2}$ Dinas Peternakan dan Perikanan Kabupaten Gowa \\ *Korespondensi Email: jumriah.syam@uin-alauddin.ac.id
}

\begin{abstract}
ABSTRAK
Program Inseminasi Buatan (IB) berdampak positip terhadap peningkatan performa sapi lokal. Namun, pemilihan penggunaan straw sapi donor yang tidak memperhatikan kondisi induk sapi lokal, berisiko pada mortalitas induk dan anak sapi saat melahirkan (partus). Penelitian ini bertujuan menemukan bagaimana tingkat mortalitas induk dan anak sapi saat partus pada Program Inseminasi Buatan (IB) serta penggunaan jenis straw yang menyebabkan mortalitas saat melahirkan (partus). Penelitian menggunakan metode survey studi kasus pada pelaksanaan Program Inseminasi Buata (IB) tahun 2016 -2017 di Kelurahan Tassililu Kecamatan Sinjai Barat Kabupaten Sinjai. Populasi penelitian berdasarkan angka Conception Rate (CR) sebanyak 213 ekor, dengan jumlah sampel 199 ekor. Hasil penelitian menemukan, tingkat mortalitas induk sapi saat melahirkan (partus) pada tahun 2016 sebesar $9.09 \%$ dan tahun 2017 sebesar 5,61 \%, sedangkan kematian anak pada tahun 2016 sebesar 3,63 \% dan tahun 2017 sebesar 2,24 \%. Mortalitas induk saat melahirkan (partus) lebih tinggi pada penggunaan straw sapi subtopis, yaitu pada penggunaan straw sapi Limousin dan sapi Simental. Pemilihan dan penggunaan straw donor yang dideposisikan pada sapi lokal, hendaknya memperhatikan kondisi induk serta pentingnya manajemen pemeliharaan untuk menghindari terjadinya distoskia yang mengakibatkan mortalitas saat melahirkan (partus).
\end{abstract}

Kata kunci: Induk dan Anak, Inseminasi Buatan, Mortalitas, Partus

\section{ABSTRACT}

The Artificial Insemination Program (IB) has a positive impact on improving the performance of local cows. However, the selection of straw donors who did not pay attention to the condition of local cows risked the mortality of the mother and calf during delivery (parturition). This study aims to find out how the parent and calf mortality rates during parturition in the Artificial Insemination Program (IB) and the use of straw types that cause mortality during childbirth (parturition). The study used a case study survey method on the implementation of the 2016 -2017 Artificial Insemination Program (IB) in Tassililu Sub-District, West Sinjai District, Sinjai District. The study population was based on 213 
Conception Rate (CR), with 199 samples. he results of the study found that the maternal mortality rate during childbirth in 2016 was $9.09 \%$ and in 2017 was $5.61 \%$, while child mortality in 2016 was $3.63 \%$ and 2017 was $2.24 \%$. The maternal mortality at delivery (parturition) is higher in the use of subtopical straw cattle, namely in the use of straw Limousin cattle and Simental cattle. The selection and use of straw donors deposited in local cattle should pay attention to the condition of the parent and the importance of maintenance management to avoid the occurrence of dystocia which results in mortality during delivery (parturition) to the condition of the parent and the importance of maintenance management to avoid the occurrence of dystocia which results in mortality during delivery (parturition)

Keywords: Artificial Insemination, Mortality, Cattle Cows and Calfs, Parturitation

\section{PENDAHULUAN}

Kebutuhan daging dari tahun ke tahun mengalami peningkatan, namun kemampuan produksi dalam negeri belum mampu memenuhi permintaan tersebut, sehingga kebijakan impor seringkali menjadi pilihan pemerintah. Kekurangan pasokan sapi dapat menguras sapi lokal untuk segera dipotong, baik sapi jantan, sapi betina (indukan) dan sapi perah (Deny 2017). Guna mengatasi permasalahan yang ada, Pemerintah melakukan kebijakan jangka pendek berupa stabilisasi harga daging sapi melalui operasi pasar, transparansi jumlah sapi di usaha penggemukan, dan impor terkendali melalui Bulog. Kebijakan jangka panjang program peningkatan produksi daging sapi nasional tetap diupayakan. Pengembangan sapi lokal perlu diperkuat serta pelaksanaan program Inseminasi Buatan di kalangan peternak (Sucipto 2015).

Inseminasi Buatan (IB) adalah teknik memasukkan mani atau semen ke dalam alat reproduksi ternak betina sehat untuk dapat membuahi sel telur dengan menggunakan alat inseminasi dengan tujuan agar ternak bunting (Feradis 2010; Kementan Republik Indonesia 2014). Program Inseminasi Buatan (IB )bertujuan untuk meningkatkan mutu genetik ternak yaitu meningkatnya kelahiran ternak unggul yang mempunyai mutu genetik tinggi seperti jenis Simmental, Limousine, Brangus dan Brahman. Selama ini perkembangbiakan sapi potong untuk memperoleh bakalan pada umumnya melalui metode perkawinan silang (cross breeding) antara rumpun sapi betina asli/lokal dengan rumpun sapi Bos Taurus melalui program Inseminasi Buatan (IB). Sapi potong hasil kawin silang disenangi oleh peternak karena pertumbuhan badannya lebih cepat dan harganya lebih tinggi dibandingkan dengan sapi potong lokal (Hunter 1995). Di Indonesia sapi hasil kawin silang antara Simental 
dengan PO mempunyai keunggulan pada bobot badan yang lebih besar dan kawin pertama yang lebih cepat dibandingkan dengan sapi hasil kawin silang lainnya (Siregar et al. 1999).

Dampak kombinasi gen yang terjadi pada sapi persilangan, dapat bersifat positif (menguntungkan) maupun negatif (merugikan) terhadap performa reproduksi sapinya. Pemunculan sifat genetik (fenotipe) seekor sapi, hampir selalu dipengaruhi oleh keadaan lingkungan tempat ternak hidup dengan atau tanpa ditambah pengaruh interaksi antara keduanya (Hammack 2004). Dampak positif program Inseminasi Buatan (IB), apabila kombinasi gen anak dari hasil perkawinan tersebut menyebabkan terjadinya peningkatan efisiensi produksi atau reproduksi, sedangkan dampak negatif jika kombinasi gen yang muncul, menyebabkan terjadinya penurunan efisiensi reproduksi seperti tingginya angka kematian induk pada saat melahirkan (partus). Tingginya tingkat kematian induk berdampak pula pada tingkat kematian anak yang dilahirkan. Kematian induk pada saat melahirkan (partus) karena kesulitan melahirkan biasa disebut distoskia. Distoskia dapat diakibatkan oleh berbagai faktor seperti adanya penyakit pada rahim, kesulitan melahirkan yang dialami oleh induk. akibat fetus yang sangat besar, kesalahan dalam memilih bibit straw yang akan di deposisikan pada uterus sapi betina. Berdasarkan uraian sebelumnya, maka perlu dilakukan suatu penelitian bagaimana tingkat mortalitas induk dan anak sapi saat partus pada program IB (Inseminasi Buatan) di Kecamatan Sinjai Barat Kabupaten Sinjai.

Berdasarkan latar belakang yang telah diuraikan diatas, maka rumusan masalahnya adalah bagaimana tingkat mortalitas induk dan anak sapi saat partus pada program IB (Inseminasi Buatan) di Kecamatan Sinjai Barat Kabupaten Sinjai. Tujuan dari penelitian ini yaitu untuk mengetahui tingkat mortalitas induk dan anak sapi saat partus pada program IB (Inseminasi Buatan) di Kecamatan Sinjai Barat Kabupaten Sinjai. Hasil penelitian ini diharapkan dapat dijadikan sebagai sumber informasi kepada berbagai pihak terkait tingkat mortalitas induk dan anak sapi saat partus pada program IB (Inseminasi Buatan) di Kecamatan Sinjai Barat Kabupaten Sinjai.

\section{METODE PENELITIAN}

\section{Jenis dan Lokasi Penelitian}

Penelitian ini dilaksanakan pada bulan Agustus sampai dengan September 2017 di Kelurahan Tassililu, Kecamatan Sinjai Barat, Kabupaten Sinjai, Provinsi Sulawesi Selatan. Populasi dalam penelitian ini adalah jumlah induk sapi betina pada Program Inseminasi 
Buatan (IB) tahun 2016, berdasarkan angka Conception Rate (CR) sebanyak 213 ekor. Sampel dalam penelitian ini adalah induk sapi betina berdasarkan angka Conception Rate (CR) pada Program Inseminasi Buatan (IB) tahun 2016 , yang mengalami partus di bulan September 2016 - Agustus 2017 , sebanyak 199 ekor.

\section{Sumber dan Metode Pengumpulan Data}

Sumber data adalah Dinas Peternakan Kabupaten Sinjai, Badan Pusat Statistik.Variabel yang diamati dalam penelitian adalah mortalitas induk dan anak sapi saat partus pada program Inseminasi Buatan. Metode penelitian menggunakan pendekatan kuantitatif studi kasus. Jenis dan sumber data dalam penelitian ini terdiri dari :

a) Data primer adalah data yang diperoleh pada saat survey bersumber dari peternak dan petugas Inseminasi

b) Data sekunder adalah data yang diperoleh artikel/ /jurnal yang mendukung penelitian serta laporan pelaksanaan IB terkait pada pelaksanaan program Inseminasi Buatan di Kabupaten Sinjai

Pengumpulan data menggunakan metode survey. Analisis data secara statistik kuatitatif berdasarkan rumus:

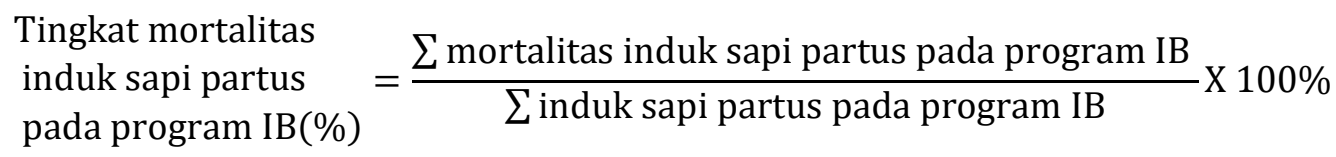

$\begin{gathered}\text { Tingkat mortalitas } \\ \text { anak sapi pada } \\ \text { program IB(\%) }\end{gathered}=\frac{\sum \text { mortalitas anak hasil IB }}{\sum \text { kelahiran anak hasil IB }} \times 100 \%$

$\begin{gathered}\text { Tingkat mortalitas } \\ \text { induk partus } \\ \text { berdasakan jenis semen }\end{gathered}$
$\sum \begin{gathered}\text { mortalitas induk partus keseluruhan } \\ \text { jenis semen yang ikut program IB }\end{gathered}$

\section{HASIL DAN PEMBAHASAN}

\section{Kondisi Geografis, Administrasi dan Perkembangan Sapi Potong di Kabupaten Sinjai}

Kabupaten Sinjai adalah salah satu kabupaten di Provinsi Sulawesi Selatan, dengan Ibu kota kabupaten di Balangnipa atau Kota Sinjai yang berjarak sekitar $\pm 220 \mathrm{~km}$ dari Kota Makassar. Kabupaten ini memiliki luas wilayah 819,96 km², terdiri atas 9 kecamatan yaitu: 
Bulupoddo, Pulau Sembilan, Sinjai Barat, Sinjai Borong, Sinjai Selatan, Sinjai Tengah, Sinjai Timur, Sinjai Utara dan Tellu Limpoe, 70 Desa/Kelurahan serta jumlah penduduk \pm 236.497 jiwa. Luas wilayah Kecamatan Sinjai Barat 135.53 km² dengan jumlah penduduk 24.311 Jiwa. Batasan wilayah Kecamatan Sinjai Barat ditunjukkan pada gambar 1. Secara administratif berbatasan:

- Sebelah Utara berbatasan dengan Kabupaten Bone;

- Sebelah Timur berbatasan dengan Teluk Bone;

- Sebelah Selatan berbatasan dengan Kabupaten Bulukumba; dan

- Sebelah Barat berbatasan dengan Kabupaten Gowa.

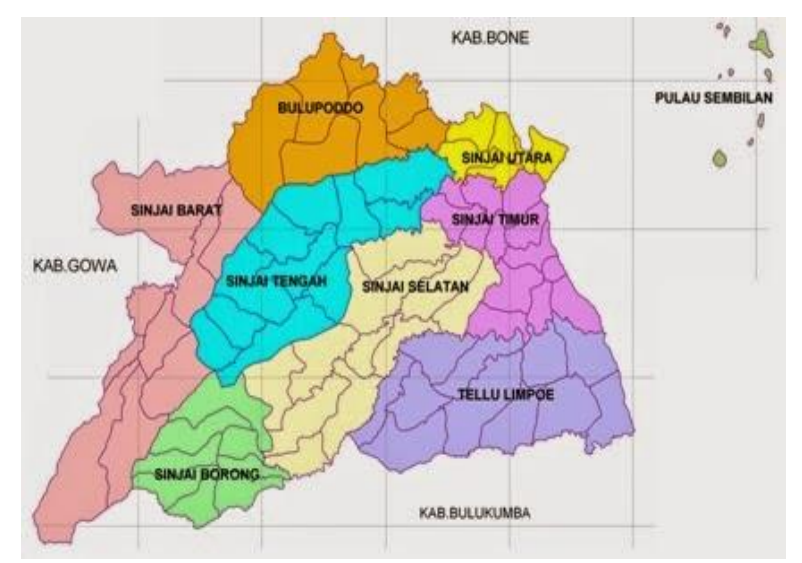

Gambar 1. Peta Lokasi Penelitian

Perkembangan subsektor peternakan di Kabupaten Sinjai, dapat dilihat dari perkembangan populasi sapi potong 5 tahun terakhir, ditunjukkan pada grafik 1 .

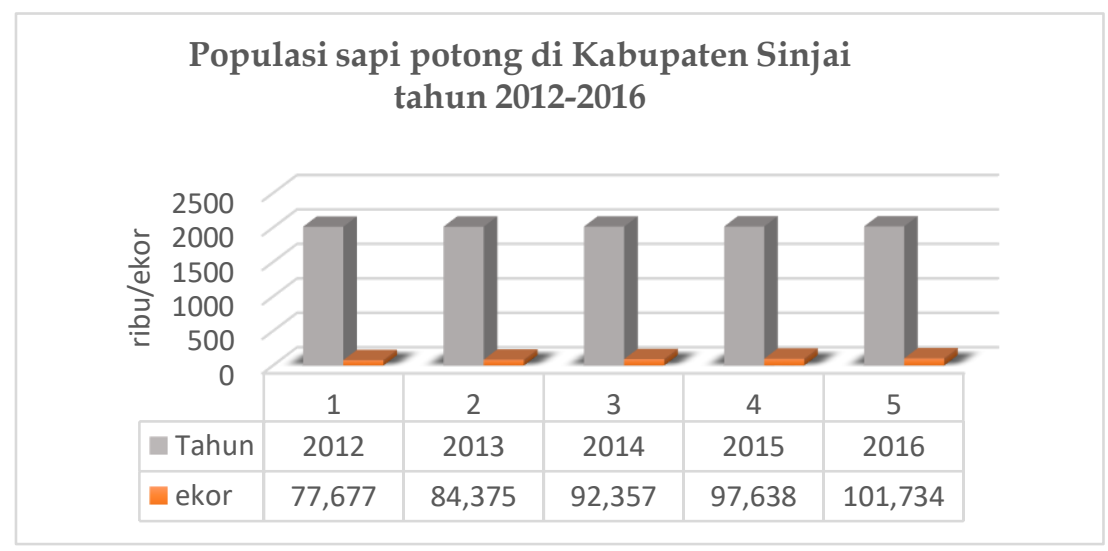

Gambar 2. Perkembangan Populasi Sapi Potong di Kabupaten Sinjai Tahun 2012-2017 
Gambar 2 menunjukkan populasi setiap tahunnya mengalami pertumbuhan yang berbeda-beda, namun memilik persamaan yaitu pertumbuhan kearah trend positif.

\section{Program Inseminasi Buatan (IB) di Kecamatan Sinjai Barat Kabupaten Sinjai}

Inseminasi Buatan (IB) merupakan program yang telah dikenal oleh peternak sebagai teknologi reproduksi ternak yang efektif. Secara umum teknik Inseminasi Buatan (IB) terdiri dari dua metode yakni metode inseminasi vaginaskop atau spekulum dan metode rectovaginal. Keberhasilan kebuntingan dipengaruhi oleh beberapa faktor, salah satu faktor yang dominan adalah posisi deposisi semen dalam saluran reproduksi ternak betina (Selk 2002). Pelaksanaan program Inseminasi Buatan (IB) harus melibatkan berbagai komponen mulai pemerintah pusat, propinsi dan kabupaten serta peternak agar pelaksanaan program Inseminasi Buatan (IB) bisa berjalan dengan baik dan mendapat hasil yang maksimal.

Tabel 1. Jumlah Sapi pada Program Inseminasi Buatan (IB) di Kelurahan Tassililu Kecamatan Sinjai Barat Kabupaten Sinjai tahun 2016-Agustus 2017

\begin{tabular}{ccc}
\hline No & Tahun & Jumlah Sapi yang Inseminasi Buatan (IB) (ekor) \\
\hline 1 & 2015 & 187 \\
2 & 2016 & 213 \\
3 & 2017 & 231
\end{tabular}

Tabel 1 menunjukkan bahwa di Kelurahan Tassililu Kecamatan Sinjai Barat Kabupaten Sinjai, jumlah ternak yang di Inseminasi Buatan (IB) mengalami peningkatan dari tahun ke tahun. Keberhasilan program Inseminasi Buatan (IB), berdasarkan dari peningkatan jumlah ternak yang ikut dalam program, karena faktor lingkungan sangat mendukung di Kecamatan Sinjai Barat Kabupaten Sinjai. Daerah tersebut memiliki iklim sub tropis dengan cuaca yang tidak terlalu dingin dan tidak terlalu panas, iklim merupakan salah satu faktor lingkungan yang berpengaruh langsung terhadap produktivitas ternak (Williamson and Payne 1993). Manajemen pemeliharaan ternak juga merupakan salah satu faktor yang dapat menyebabkan rendahnya tingkat mortalitas pada induk sapi hal ini disebabkan, karena dengan manajemen pemeliharaan yang baik semua aktivitas dan kebutuhan ternak terpenuhi (Syam 2014), manajemen peternakan dibagi menjadi tiga proses mulai dari pemilihan bibit, pakan dan pencegahan penyakit, proses produksi serta hasil dan 
penanganannya harus terpenuhi agar lancar dan seimbang (Sudarmono and Sugeng 2008, 2016).

Tingkat mortalitas induk dan anak sapi saat partus pada Program Inseminasi Buatan (IB) di Kecamatan Sinjai Barat Kabupaten Sinjai

Tingkat mortalitas induk dan anak sapi saat partus adalah banyaknya atau jumlah kematian induk dan anak sapi saat melahirkan ataupun anak sapi setelah kelahiran hidup mengalami kematian akibat kematian induk pada saat melahirkan, tingkat mortalitas adalah jumlah kematian (Kamus besar bahasa Indonesia (KBBI Online) 2017), . Kematian adalah hilangnya semua tanda-tanda kehidupan secara permanen yang bisa terjadi setiap saat setelah kelahiran hidup.

Tabel 2. Jumlah Conception Rate (CR) induk sapi dan Jumlah Induk Sapi Sapi Partus Hasil Conception Rate (CR) pada Program Inseminasi Buatan (IB) di Kecamatan Sinjai Barat Kabupaten Sinjai tahun 2016

\begin{tabular}{cccc}
\hline \multirow{2}{*}{ Jumlah CR (ekor) } & \multicolumn{2}{c}{ Jumlah Sapi Partus Hasil CR } & \multirow{2}{*}{ Jumlah (ekor) } \\
\cline { 2 - 4 } & 2016 & 2017 & 199 \\
\hline 213 & 110 & 89 & \\
\hline
\end{tabular}

Tabel 2 menunjukkan, bahwa pada tahun 2016 jumlah Conception Rate (CR) sapi pada program Inseminasi Buatan (IB) sebanyak 213 ekor. Jumlah keseluruhan sapi partus hasil Conception Rate sebanyak 199 ekor sampai Agustus 2017, sedangkan sapi yang belum partus sebanyak 14 ekor. Hal tersebut dikarenakan data penelitian yang diperoleh hanya mulai dari tahun 2016 sampai bulan Agustus 2017.

Tabel 3. Tingkat mortalitas induk dan anak sapi saat partus pada program Inseminasi Buatan (IB) di Kecamatan Sinjai Barat Kabupaten Sinjai tahun 2016-Agustus 2017

\begin{tabular}{lllllllll}
\hline \multirow{3}{*}{$\begin{array}{c}\text { Jumlah sapi partus hasil CR } \\
\text { tahun 2016 (ekor) }\end{array}$} & \multicolumn{5}{c}{ Tingkat Mortalitas (ekor) } \\
\cline { 3 - 8 } \multicolumn{3}{c}{} & \multicolumn{5}{c}{ Induk } \\
\hline 2016 & 2017 & Jumlah & 2016 & 2017 & Jumlah & 2016 & 2017 & Jumlah \\
\hline 110 & 89 & 199 & 10 & 5 & 15 & 4 & 2 & 6 \\
\hline
\end{tabular}

Tabel 3 menunjukan, bahwa jumlah mortalitas induk lebih tinggi dari jumlah mortalitas anak. Jika ditinjau dari segi ekonomi, kematian induk dan kematian anak 
mempengaruhi kelangsungan usaha peternakan, yaitu sama-sama merugikan. Namun, jumlah mortalitas induk yang lebih tinggi daripada kematian anak dapat menyebabkan kerugian yang lebih besar bagi peternak. Hal tersebut disebabkan, apabila induk sapi yang mengalami mortalitas maka kelangsungan reproduksi akan berhenti. Jika anak sapi yang mengalami mortalitas, maka induk sapi masih dapat berproduksi diperiode selanjutnya. Angka kelahiran dan pertambahan populasi ternak adalah masalah reproduksi atau perkembangbiakan ternak. Penurunan angka kelahiran dan meningkatnya tingkat kematian menyebabkan penurunan populasi ternak (Toelihere 1985). Olehnya itu, kematian induk dan anak merupakan masalah kontinuitas reproduksi ternak. Data pada tabel 3 jika di persentasekan dapat diilustrasikan pada Grafik 2

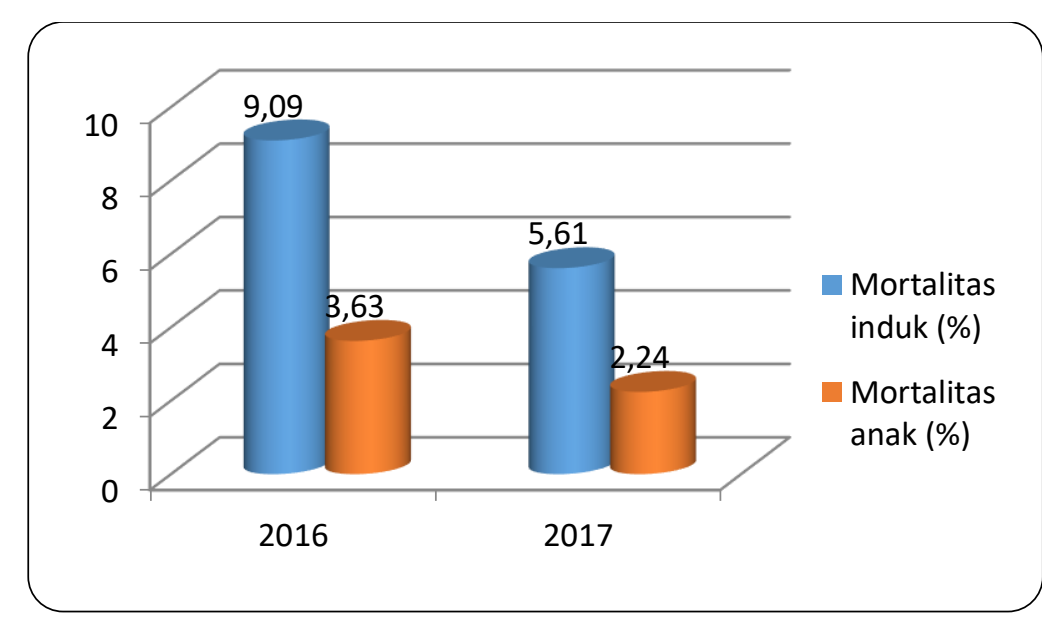

Grafik 3. Persentase mortalitas induk dan anak sapi saat partus pada Program Inseminasi Buatan (IB) di Kecamatan Sinjai Barat Kabupaten Sinjai tahun 2016Agustus 2017

Gambar 3 menunjukkan, bahwa persentase tingkat mortalitas induk lebih tinggi dari pada anak sapi, hal ini antara lain disebabkan keterlambatan peternak dalam memberikan informasi kepada petugas inseminator. Induk ternak yang bunting hasil Inseminasi Buatan (IB) saat melahirkan (partus), terkadang membutuhkan bantuan teknis dari inseminator/ dokter hewan jika mengalami distoskia. Menurut (Partodihardjo 1992), tingginya tingkat kematian pada induk sapi hasil IB disebabkan karena kurangnya ketelitian peternak. Faktor lingkungan termasuk faktor yang dapat meningkatkan kematian induk dan anak sapi hasil Inseminasi Buatan (IB). Lingkungan yang kotor dapat menyebabkan terjadinya kontaminasi 
mikroorganisme yang berdampak pada kematian anak sapi hasil IB. Lingkungan yang kurang higienis dapat meningkatkan tingginya angka kematian pada anak sapi hasil Inseminasi Buatan (IB) (Hunter 1995)

Lama proses kelahiran juga dapat menjadi salah satu penyebab tingginya tingkat mortalitas pada saat partus. Hal tersebut dikenal dengan istilah Distokia. Distokia adalah suatu gangguan dari suatu proses kelahiran dimana fetus lebih lama dan sulit dikeluarkan, sehingga dapat menyebabkan kematian pada induk dan anak sapi (Jackson 2009; Putro, Prihatno, and Setiawan 2012). Hal tersebut disebabkan karena kurang baiknya manajemen pemberian pakan. Hal ini sesuai dengan pendapat Salisburi (1985), yang menyatakan bahwa pemberian pakan yang terlalu banyak dapat menyebabkan meningkatnya berat fetus, timbunan lemak intrapelvis serta beresiko besar mengalami distokia dan dampaknya berpengaruh pada kematian anak sapi hasil Inseminasi Buatan (IB).

Tabel 4. Jumlah mortalitas induk sapi berdasarkan jenis straw yang digunakan pada Program Inseminasi Buatan (IB) di Kecamatan Sinjai Barat Kabupaten Sinjai tahun 2016Agustus 2017

\begin{tabular}{|c|c|c|c|c|c|}
\hline \multirow{2}{*}{ No } & \multirow{2}{*}{ Jenis Straw } & \multicolumn{4}{|c|}{ Mortalitas Induk } \\
\hline & & 2016 (Ekor) & Jumlah (\%) & 2017 (Ekor) & Jumlah (\%) \\
\hline 1 & Limousin & 4 & 40 & 2 & 40 \\
\hline 2 & Brahman & 3 & 30 & - & 0 \\
\hline 3 & Bali & 3 & 30 & - & 0 \\
\hline 4 & Simental & - & 0 & 3 & 60 \\
\hline
\end{tabular}

Tabel 4 menunjukan, bahwa mortalitas tertinggi induk sapi pada saat melahirkan (partus) berdasarkan penggunaan jenis straw pada Program Inseminasi Buatan (IB) di tahun 2016 didapatkan pada penggunaan straw Sapi Limousin. Penggunaan straw sapi Limousin tidak memperhatikan bentuk tubuh induk, artinya induk sapi yang tubuhnya kecil didesposisi dengan straw sapi Limousin, akibatnya terjadi distoskia saat melahirkan (partus), yang pada akhirnya mengakibatkan kematian pada induk dan anak. Menurut (Salisbury, VanDemark, and Lodge 1978) distokia adalah suatu gangguan dari suatu proses kelahiran atau partus, yang mana dalam stadium pertama dan stadium kedua dari partus itu keluarnya fetus menjadi lebih lama dan sulit, sehingga menjadi tidak mungkin kembali bagi induk untuk mengeluarkan fetus kecuali dengan pertolongan manusia. Distokia umumnya terjadi pada induk yang baru pertama kali beranak, induk yang masa kebuntingannya jauh 
melebihi waktu normal, induk yang terlalu cepat dikawinkan, hewan yang kurang bergerak, kelahiran kembar dan penyakit pada rahim. Distoskia yang dialami induk pada program Inseminasi Buatan (IB), dapat disebabkan tubuh induk tidak seimbang dengan ukuran (besarnya) fetus. Fetus yang sangat besar, menyulitkan induk saat melahirkan (pastus). Hal lainnya, dapat diakibatkan kebuntingan induk yang lebih lama dari waktu normal. Sapi yang bunting lebih lama dapat meningkatkan berat anak sapi rata-rata $0,5 \mathrm{~kg} /$ per hari dan panjang tulang fetus juga meningkat (Jackson 2009)Sapi Induk sapi yang digunakan pada umumnya adalah sapi Bali yang termasuk dalam bangsa sapi tropis, sedangkan straw yang digunakan adalah bangsa sapi subtropis. Sapi Limousin merupakan bangsa sapi subtropis dengan ukuran bobot badan yang besar, yaitu bobot betina dewasa dapat mencapai $585 \mathrm{~kg}$ dan jantan dewasa berat mencapai 1100 kg., dengan keunggulan pertumbuhan badan sangat cepat, dan kualitas daging tinggi. Kemampuan genetik tersebut, harus didukung oleh manajemen pemberian pakan yang baik untuk mendapatkan hasil yang optimal (Syam 2013, 2014). Distoskia yang dialami induk sapi Program Inseminasi Buatan (IB) di Kecamatan Sinjai barat Kabupaten Sinjai, dapat pula disebabkan oleh faktor lingkungan dan faktor intrinsik (Jackson 2009)

Pada tahun 2017, kematian induk sapi saat melahirkan (partus) ditemukan pada penggunaan straw Sapi Simental menyusul Sapi Limousin. Kedua bangsa sapi ini tergolong bangsa sapi subtropis dengan ukuran badan yang besar (Syam 2013), sehingga strawnya disenangi oleh peternak, dengan harapan anak yang dihasilkan memiliki ukuran tubuh yang besar. Sapi Simental secara genetik adalah sapi potong yang berasal dari wilayah beriklim dingin, merupakan sapi tipe besar, mempunyai volume rumen yang besar, kemampuan menambah konsumsi diluar kebutuhan yang sebenarnya yang tinggi, dan laju metabolisme yang cepat, sehingga menuntut tata laksana pemeliharaan yang lebih teratur (Samsul and Dadi 2010). Kematian yang disebabkan penggunaan straw sapi yang berasal dari bangsa sapi subtropis di tahun 2016 ditemukan pula, tetapi di tahun 2017 kasus mortalitas tidak ada Rendahnya mortalitas kematian induk sapi dengan penggunaan straw bangsa sapi tropis dibandingkan dengan straw bangsa sapi subtropis, disebabkan ukuran tubuh induk dengan straw donor yang digunakan tidak jauh berbeda, sehingga kesulitan saat melahirkan (partus) jarang ditemukan. Olehnya itu, pemilihan straw donor yang digunakan pada Program Inseminasi Buatan (IB), hendaknya memperhatikan ukuran tubuh induk, agar kematian saat melahirkan (partus) dapat diminimalisir. 


\section{KESIMPULAN}

a. Tingkat mortalitas induk sapi saat melahirkan (partus) pada Program Inseminasi Buatan (IB) padat tahun 2016 sebesar 9.09 \% dan tahun 2017 sebesar 5,61 \%, sedangkan kematian anak pada tahun 2016 sebesar 3,63 \% dan tahun 2017 sebesar 2,24 \%.

b. Mortalitas induk saat melahirkan (partus) lebih tinggi pada penggunaan straw bangsa sapi subtopis dibandingkan bangsa sapi tropis. Angka tertinggi pada penggunaan straw sapi Limousin dan sapi Simental

c. Pemilihan straw donor yang dideposisikan pada Program Inseminasi Buatan (IB), hendaknya memperhatikan kondisi induk serta pentingnya manajemen pemeliharaan untuk menghindari terjadinya distoskia yang mengakibatkan mortalitas saat melahirkan (partus)

\section{DAFTAR PUSTAKA}

Deny, S. 2017. “RI Berpotensi Kekurangan Pasokan Daging Sapi Di 2017." Liputan 6: 12.https://www.liputan6.com/bisnis/read/2613378/ri-berpotensi-kekuranganpasokan-daging-sapi-di-2017.

Feradis. 2010. Bioteknologi Reproduksi Pada Ternak. Cetakan ke. Penerbit Alfabeta, Bandung.

Hunter, R.H.F. 1995. Fisiologi Dan Teknologi Reproduksi Hewan Betina Domestik. Institut Teknologi Bandung., Bandung.

Jackson., Peter, G. G. 2009. Handbook Obstetri Veteriner. Edisi 2. Yogyakarta: Gadjah Mada University Press.

Kamus besar bahasa Indonesia (KBBI Online). 2017. "Mortalitas." https://kbbi.web.id/mortalitas.

Kementan Republik Indonesia. 2014. “Undang-Undang Peternakan Dan Kesehatan Hewan No 41 Tahun 2014." : http://ditjenpkh.pertanian.go.id/userfiles/regulasi/abcf589a34b48ddb743ffc5bdfb50d 87.pdf.

Partodihardjo, Soebadi. 1992. Ilmu Reproduksi Hewan. Cetakan ke. Jakarta: Penerbit Mutiara.

Putro, P.P., Prihatno, S.A., and Setiawan, E.M.N. 2012. “Petunjuk Praktikum Ruminansia I Blok115."

Salisbury, G. W., VanDemark, N. L. and Lodge, J. R. 1978. Physiology of Reproduction and Artificial Insemination of Cattle. 2nd ed. San Francisco: W.H. Freeman and Company.

Samsul., Fikar, dan Dadi, R. 2010. Buku Pintar Beternak \& Bisnis Sapi Potong. gro Media Pustaka, Jakarta.

Selk, G. 2002. "Artificial Insemination for Beef Cattle." http://www.thecattlesite.com/articles/721/artificial-insemination-for-beef-cattle/.

Sucipto. 2015. "Produksi Sapi Nasional Dan Perbaikan Sistem Logistik." BeritaSatu. https://id.beritasatu.com/home/produksi-sapi-nasional-dan-perbaikan-sistemlogistik/125166 (July 6, 2017). 
Sudarmono, A. S., dan Sugeng, Y.B. 2016. Panduan Beternak Sapi Potong. Penebar Swadaya, Jakarta.

Sudarmono, A.S., dan Sugeng, B. 2008. Sapi Potong (Revisi). Revisi. Jakarta: Penebar Swadaya.

Syam, J. 2013. Ilmu Dasar Ternak Potong. ed. M Anshar. Makassar: Alauddin University Press.

. 2014. Manajemen Ternak Potong dan Kerja. ed. Andi Suarda. Makassar: Alauddin University Press.

Toelihere, M. R. 1985. Inseminasi Buatan Pada Ternak. Angkasa, Bandung

Williamson, G, dan Payne, W.J.A. 1993. Pengantar Peternakan Di Daerah Tropis. Gadjah Mada University Press, Yokyakarta 